Пробл. особо опасных инф. 2016; 4:88-92. DOI: 10.21055/0370-1069-2016-4-88-92

УДК 616.932:579.61

\author{
Н.Б.Челдышова, А.А.Крицкий, Ю.В.Лозовский, Н.П.Гусева \\ СРАВНИТЕЛЬНЫЙ MLVA-АНАЛИЗ ШТАММОВ VIBRIO CHOLERAE \\ КЛАССИЧЕСКОГО БИОВАРА, ВЫДЕЛЕННЫХ В РОССИИ И ЗА РУБЕЖОМ
}

ФКУЗ «Российский научно-исследовательский противочумныий институт «Микроб», Саратов, Российская Федерацчия

Цель работы. Определение филогенетического родства штаммов $V$. cholerae классического биовара, выделенных в период с 1937 по 1969 год в России, со штаммами из ближнего и дальнего зарубежья. Материалы и методы. В работе использовано 27 штаммов Vibrio cholerae классического биовара. ПЦР проводили на амплификаторе «БИС М112». Для секвенирования использовали генетический анализатор ABI 3500xl. MLVA-анализ вели по 5 MLVA-локусам (VC0147, VC0436-0437, VC1650, VCA0171, VCA0283). Питательные потребности и продукцию растворимой гемагглютинин/протеазы определяли чашечным методом. Результаты и выводы. Выявлено 8 MLVA-кластеров и 21 MLVA-тип. Установлено, что штаммы, выделенные в период атипичной вспышки холеры в России в 1942-1943 гг., фено- и генотипически неоднородны и относятся к двум различным группам, одна из которых родственна изоляту, выделенному при вспышке холеры в Хабаровске в 1938 г., а вторая - штаммам из Индии и Китая, выделенным в 1946 и 1949 гг. соответственно.

Ключевые слова: V. cholerae классического биовара, MLVA-кластер, MLVA-тип, MLVA-профиль.

Корреспондирующий автор: Надежда Борисовна Челдышова, e-mail: rusrapi@microbe.ru.

\title{
N.B.Cheldyshova, A.A.Kritsky, Yu.V.Lozovsky, N.P.Guseva \\ Comparative MLVA-Analysis of Vibrio cholerae Strains of Classical Biovar, Isolated in the Russian Federation and Abroad
}

Russian Research Anti-Plague Institute "Microbe”, Saratov, Russian Federation

Objective of the study is to determine phylogenetic affinity of the Vibrio cholerae strains of classical biovar, isolated between 1937 and 1969 in Russia, to the strains from near and far abroad countries. Materials and methods. Utilized were 27 Vibrio cholerae strains of classical biovar. PCR was carried out applying "BIS M112" amplifier. Genetic analyzer ABI 3500xl was used for sequencing of the strains. MLVA-analysis was performed by reference to 5 MLVA-loci: VC0147, VC0436-0437, VC1650, VCA0171, and VCA0238. Nutrient requirement and soluble hemagglutinin/protease production was established using plate method. Results and conclusions. Identified have been 8 MLVA-clusters and 21 MLVA-types. It is determined that the strains, isolated during atypical cholera outbreak 1942-1943 in Russia, are inhomogeneous as regards phenotype and genotype and fall into two separate groups, one of which is related to the strain, isolated during cholera outbreak 1938 in Khabarovsk, and another group - to the strains from India and China, isolated in 1946 and 1949, respectively.

Key words: V. cholerae of classical biovar, MLVA-cluster, MLVA-type, MLVA-profile.

Conflict of interest: The authors declare no conflict of interest.

Corresponding author: Nadezhda B. Cheldyshova, e-mail: rusrapi@microbe.ru.

Citation: Cheldyshova N.B., Kritsky A.A., Lozovsky Yu.V., Guseva N.P. Comparative MLVA-Analysis of Vibrio cholerae Strains of Classical Biovar, Isolated in the Russian Federation and Abroad. Problemy Osobo Opasnykh Infektsii [Problems of Particularly Dangerous Infections]. 2016; 4:88-92. (In Russ.). DOI: 10.21055/03701069-2016-4-88-92

Vibrio cholerae классического биовара считается возбудителем первых шести пандемий холеры, отличавшихся тяжелым течением болезни и высокой летальностью (около 42-50 \%) [2, 4, 5]. В 60-х годах $\mathrm{XX}$ столетия произошла смена биовара возбудителя холеры с классического на биовар Эль Тор, явившийся причиной 7-й пандемии холеры. Холерные вибрионы биовара Эль Тор достаточно быстро распространились по всему земному шару, практически полностью вытеснив классические холерные вибрионы. Однако полного прекращения циркуляции холерных вибрионов классического биовара не произошло. Несмотря на то, что 6-я пандемия холеры закончилась к 1926 г., отдельные вспышки классической (азиатской) холеры продолжали регистрировать вплоть до 1960 г. в Индии, Китае, Пакистане,
Афганистане и других странах [2]. В России в этот период произошло две вспышки азиатской холеры. Первая из них, зафиксированная в Хабаровске в 1938 г., была быстро локализована и ликвидирована. Ее продолжительность составила 49 дней, холерой заболело 57 человек, летальных случаев не зафиксировано. Вторая, бо̀льшая по масштабам распространения, вспышка холеры, вызванная классическими вибрионами, наблюдалась на территории Нижнего Поволжья и Башкирии в 1942-1943 гг. Она отличалась нехарактерно большим для классической холеры количеством легких и стертых клинических форм, длительным вибрионосительством на фоне высокой летальности в случае тяжелого течения болезни $(41,2 \%)$ и сравнительно небольшим распространением инфекции, преимущественно контактно- 
бытовым путем [2].

Ряд крупных вспышек классической холеры наблюдался и после начала 7-й пандемии холеры: в Бангладеш в 1982, 1988-1989 гг., Мексике в 19911997 гг. и Непале в 2012 г. [6, 12, 13, 14]. Выделение единичных штаммов классического биовара отмечалось и при вспышке холеры в Иране в 2012 г. [7], а также из прибрежных вод Черного моря и внутренних водоемов в районе Тбилиси [11]. Интересен и тот факт, что, начиная с 90-х годов ХX столетия, участились случаи выделения от больных и из внешней среды штаммов, несущих признаки как классического, так и Эль Тор биоваров $[3,8,12,13]$. В настоящее время практически все выделяемые от людей токсигенные штаммы биовара Эль Тор несут в своем составе профаг с геном $\operatorname{ctxB} 1$, характерным для классических вибрионов [3]. В связи с этим некоторыми авторами высказано предположение о его получении непосредственно от холерных вибрионов классического биовара [12]. Все вышесказанное свидетельствует о том, что холерные вибрионы классического биовара, несмотря на то, что утратили прежнюю эпидемическую значимость, все же способны вызывать единичные случаи и вспышки холеры, а их потенциальная способность служить донорами отдельных мобильных генетических элементов, таких как профаг СТХ $\varphi$ с геном $c t x B 1$, ответственным за синтез В-субъединицы холерного токсина классического типа. Это говорит о необходимости их дальнейшего изучения.

Согласно исследованиям зарубежных и отечественных авторов, геном холерных вибрионов классического биовара в отличие от генома Эль Тор вибрионов является достаточно стабильным по присутствию основных детерминант вирулентности [9]. В то же время до сих пор остается недостаточно изученным вопрос о геномном разнообразии классических штаммов холерного вибриона и их филогенетических связях.

Целью данной работы явилось определение филогенетического родства штаммов V. cholerae классического биовара, выделенных в период с 1937 по 1969 год в России, со штаммами из ближнего и дальнего зарубежья.

Для этих целей нами был использован метод MLVA-типирования (MLVA - от Multiple-Locus Variable number tandem repeat Analysis) по 5 MLVAлокусам (VC0147, VC0436-0437, VC1650, VCA0171, VCA0283), хорошо зарекомендовавший себя для дифференциации холерных вибрионов биовара Эль Top. В основе метода MLVA-типирования лежит сравнительный анализ количества вариабельных повторов в 5 VNTR-локусах $[1,8]$.

\section{Материалы и методы}

В работе использовано 27 штаммов $V$. cholerae классического биовара (таблица), 13 из них было выделено в различных регионах России в 1942-1943 гг.,
1 штамм - в Хабаровске в 1938 г., 13 штаммов - на территории различных стран Средней, Южной и Юго-Восточной Азии (Туркмения, Пакистан, Индия, Китай, Корея). Указанные штаммы были получены из Государственной коллекции патогенных бактерий РосНИПЧИ «Микроб» (ГКПБ «Микроб»), где они хранились в лиофилизированном состоянии. Культивирование бактерий осуществляли на бульоне и агаре Luria-Bertani (LB).

MLVA-типирование осуществляли с помощью специфических праймеров к 5 указанным выше MLVA-локусам холерного вибриона [8]. ПЦР проводили на амплификаторе с нагреваемой крышкой «БИС M112» по программе, описанной ранее [8]. Для секвенирования полученных ампликонов использовали генетический анализатор ABI 3500xl. Первичный анализ полученной нуклеотидной последовательности и определение числа тандемных повторов проводили с помощью программы MEGA 5.0. Построение филогенетического дерева осуществляли с помощью программы «BioNumerics 7.0» (Applied Maths, Бельгия) с использованием метода «максимальной бережливости» (Maximum parsimony).

Питательные потребности штаммов холерного вибриона определяли на минимальной среде с добавлением различных аминокислот, оснований и витаминов в концентрации 20-40 мкг/мл [4]. Продукцию растворимой гемагглютинин/протеазы (HA/P - от haemagglutinin/protease) выявляли путем посева культур на агар, содержащий 1,0 \% обезжиренного молока [4].

\section{Результаты и обсуждение}

В результате проведенного мультилокусного анализа 27 штаммов холерного вибриона классического биовара выявлен 21 MLVA-тип и 8 MLVAкластеров (рисунок). Эти данные свидетельствуют о разнообразии геномов изученных штаммов классического биовара по MLVA-локусам.

В первый, наибольший по численности MLVAкластер, вошли 11 из 13 штаммов, выделенных в 1942-1943 гг. в России, что указывает на их близкое генетическое родство. Кроме того, 2 MLVA-типа в пределах этого кластера состояли сразу из 2 штаммов, что свидетельствует об их клональном происхождении. MLVA-профили этих штаммов были идентичны или отличались лишь по наиболее вариабельному локусу VCA0283 (таблица). Ни один из штаммов, выделенных в других странах, не вошел в I MLVA-кластер. Проведенные нами ранее исследования показали, что данная группа штаммов отличалась рядом фено- и генотипических особенностей. Все штаммы этой группы были ауксотрофами [4] в результате мутации в гене $p u r E$ [5]. Кроме того, они не продуцировали НА/Р, были вирулентны и обладали повышенной продукцией холерного токсина (CT - от cholera toxin) и токсин-корегулируемых пилей адгезии (ТCP - от toxin-coregulated pilus) [4], 


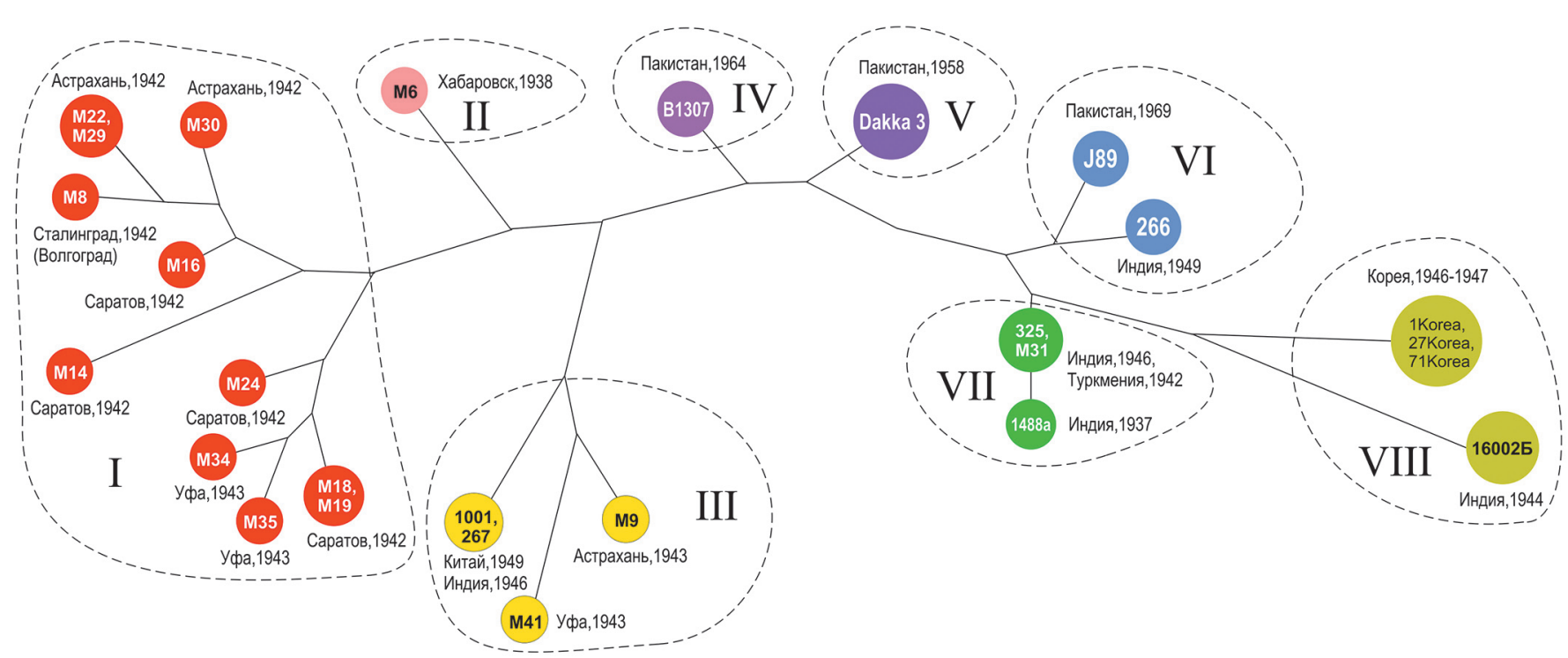

Филогенетическое дерево, построенное на основе MLVA-типирования по 5 VNTR-локусам штаммов Vibrio cholerae классического биовара, выделенных с 1937 по 1969 год на территории России и стран ближнего и дальнего зарубежья. MLVA-типы изображены кружками, в которых указаны номера, входящих в них штаммов. MLVA-типы, входящие в один MLVA-кластер, выделены одним цветом и контурной штриховкой

что, как показано нами ранее [5], связано с наличием у них ряда мутаций в регуляторных генах $r p o S$ и hapR.

Наиболее близким по MLVA-профилю к штаммам I кластера оказался штамм М6, выделенный в
Хабаровске в 1938 г., который входил во II MLVAкластер (рисунок). Его MLVA-профиль по 3 из 5 локусов был близок к I MLVA-кластеру (таблица). Исследование данного штамма на питательные потребности и продукцию НА/Р показало, что он

MLVA-профили штаммов Vibrio cholerae классического биовара

\begin{tabular}{|c|c|c|c|c|c|c|c|}
\hline \multirow[b]{2}{*}{ MLVA-кластер } & \multirow[b]{2}{*}{ № штамма } & \multirow[b]{2}{*}{ Место и год выделения } & \multicolumn{5}{|c|}{ Количество повторов в MLVA-локусах } \\
\hline & & & $\begin{array}{l}\text { VCO147 } \\
\text { AACAGA }\end{array}$ & $\begin{array}{l}\text { VC0436-0437 } \\
\text { AACAGA }\end{array}$ & $\begin{array}{c}\text { VC1650 } \\
\text { GATAATCCA }\end{array}$ & $\begin{array}{l}\text { VCA0171 } \\
\text { TGCTGT }\end{array}$ & $\begin{array}{l}\text { VCA0283 } \\
\text { ACCAGA }\end{array}$ \\
\hline I & M8 & $\begin{array}{c}\text { Сталинград (Волгоград), } \\
1942\end{array}$ & 12 & 5 & 3 & 20 & 31 \\
\hline I & M14 & Саратов, 1942 & 10 & 5 & 3 & 17 & 32 \\
\hline I & M16 & Саратов, 1942 & 12 & 5 & 3 & 12 & 22 \\
\hline I & M18 & Саратов, 1942 & 11 & 5 & 3 & 15 & 27 \\
\hline I & M19 & Саратов, 1942 & 11 & 5 & 3 & 15 & 27 \\
\hline I & M22 & Астрахань, 1942 & 12 & 5 & 3 & 16 & 26 \\
\hline I & M24 & Саратов, 1942 & 11 & 5 & 3 & 12 & 34 \\
\hline I & M29 & Астрахань, 1942 & 12 & 5 & 3 & 16 & 30 \\
\hline I & M30 & Астрахань, 1942 & 12 & 5 & 3 & 15 & 34 \\
\hline I & M34 & Уфа, 1943 & 11 & 5 & 3 & 18 & 35 \\
\hline I & M35 & Уфа, 1943 & 11 & 5 & 4 & 16 & 31 \\
\hline II & M6 & Хабаровск, 1938 & 12 & 4 & 3 & 13 & 16 \\
\hline III & 1001 & Китай, 1949 & 9 & 3 & 3 & 12 & 28 \\
\hline III & 267 & Индия, 1946 & 9 & 3 & 3 & 12 & 22 \\
\hline III & M9 & Астрахань, 1942 & 9 & 4 & 3 & 23 & 24 \\
\hline III & M41 & Уфа, 1943 & 9 & 4 & 3 & 9 & 7 \\
\hline IV & B1307 & Пакистан, 1964 & 8 & 4 & 3 & 20 & 26 \\
\hline $\mathrm{V}$ & Dakka 3 & Пакистан, 1958 & 8 & 4 & 3 & 21 & 26 \\
\hline VI & 266 & Индия, 1949 & 8 & 3 & 3 & 16 & 17 \\
\hline VI & J89 & Пакистан, 1969 & 8 & 3 & 3 & 23 & 30 \\
\hline VII & M31 & Туркмения, 1942 & 8 & 3 & 3 & 7 & 20 \\
\hline VII & $1488 \mathrm{a}$ & Индия, 1937 & 8 & 3 & 3 & 7 & 8 \\
\hline VII & 325 & Индия, 1946 & 8 & 3 & 3 & 7 & 20 \\
\hline VIII & 27 Korea & Корея, 1946 & 8 & 3 & 3 & 7 & 22 \\
\hline VIII & 71 Korea & Корея, 1946 & 8 & 3 & 3 & 7 & 20 \\
\hline VIII & 1 Korea & Корея, 1947 & 8 & 3 & 3 & 7 & 26 \\
\hline VIII & 160025 & Индия, 1944 & 9 & 3 & 3 & 11 & 22 \\
\hline
\end{tabular}


так же, как и атипичные штаммы 1942 г., является ауксотрофом по аденину и не продуцирует НА/Р. Следует отметить, что остальные 15 штаммов $V$. cholerae классического биовара были прототрофами и продуцировали достаточное количество НА/Р. Более того, в литературных источниках нам ни разу не встретилось упоминание о выделении штаммов, обладающих сразу двумя указанными фенотипическими особенностями (ауксотрофностью по аденину и отсутствием продукции НА/P). Учитывая фенотипические особенности хабаровского штамма, а также близость его MLVA-профиля c MLVA-профилем атипичных штаммов 1942 г., мы пришли к выводу, что указанные штаммы имеют близкое генетическое родство.

Штаммы M9 и M41, также выделенные в 19421943 гг. в период атипичной вспышки холеры в России, но несколько отличающиеся по фено- и генотипическим характеристикам (прототрофы, НА/ $\mathrm{P}^{+}$, гипопродукция СТ, отсутствуют мутации в генах $h a p R, \operatorname{rpoS}$ и purE $[4,5])$, были отнесены к III MLVAкластеру, как и штаммы 1001 (Китай, 1949 г.) и 267 (Индия, 1946 г.). Это говорит, во-первых, о генетическом родстве двух прототрофных штаммов 1942 г. со штаммами, выделенными через несколько лет в Индии и Китае, а во-вторых, о различном происхождении штаммов, выделенных во время вспышки холеры в России в 1942-1943 гг. MLVA-профили ауксотрофных и прототрофных штаммов, выделенных в России в 1942-1943 гг., отличались по 4 из 5 MLVA локусов (таблица).

Другие штаммы классического биовара сформировали еще 5 MLVA-кластеров, достаточно удаленных от кластеров штаммов, выделенных в России (рисунок), что свидетельствует о значительном разнообразии холерных вибрионов классического биовара по MLVA-локусам, даже в тех случаях, когда штаммы были выделены на одних и тех же территориях в разные годы. Так, три штамма, выделенные в Пакистане в 1958-1969 гг., входили в три различные MLVA-кластеры (IV, V и VI). При этом IV и V кластеры включали только по одному штамму, что говорит об их отличии от других штаммов и друг от друга. VI кластер включал штаммы из Пакистана (J-89) и Индии (266). Интересно, что, несмотря на то, что между их выделениями прошло 20 лет (штамм 266 выделен в 1949 г., а штамм J-89 - в 1969 г.), эти изоляты оказались достаточно близкими по MLVAпрофилю и отличались лишь по 2 наиболее вариабельным локусам, расположенным на II хромосоме $(8,3,3,16,17$ и $8,3,3,23,30$ соответственно), что и позволило им сформировать один MLVA-кластер. В то же время штаммы 267 и 325, выделенные в один год в Индии, отличались по 3 MLVA-локусам (таблица), в связи с чем они вошли в разные MLVA-кластеры (рисунок).

Два индийских штамма (325 и 1488a) и 1 штамм (M31), выделенный в Туркмении в 1942 г., входили в VII MLVA-кластер. При этом штаммы М31 и 325 формировали один MLVA-тип, а их MLVA-профили были идентичны $(8,3,3,7,20)$, что говорит об их клональном происхождении. В то же время, тот факт, что все три штамма располагаются на одной ветви, может свидетельствовать о том, что штаммы M31 и 325 являются близкими родственниками индийского изолята 1488a, выделенного в 1937 г. и отличающегося от двух других штаммов этого кластера только по локусу VCA0283 (таблица). Возможно, все 3 указанных штамма произошли от общего предка, циркулировавшего на территории Индии еще до 1937 г. При этом одна часть дериватов этого штамма сохранила прежний MLVA-профиль (M31 и 325) и была занесена на территорию Туркмении (M-31), а другая - под действием изменившихся факторов среды утратила 12 дополнительных повторов в указанном локусе (штамм 1488a).

Восьмой MLVA-кластер включал штаммы из Кореи (Korea 1, Korea 27 и Korea 71), выделенные в 1946-1947 гг., и штамм 16002Б из Индии 1944 г. (рисунок). С учетом того, что указанные штаммы сформировали один MLVA-кластер, можно предположить, что они произошли от общего предка. Следует также отметить клональность происхождения корейских штаммов, которые образовали один MLVA-тип, хотя и были выделены в разные годы. MLVA-профили корейских штаммов отличались только по наиболее вариабельному локусу VCA0283 (таблица).

Таким образом, в результате проведенного исследования установлено, что штаммы $V$. cholerae классического биовара, выделенные в различных регионах мира в период с 1937 по 1969 год, отличались значительным разнообразием по MLVA-локусам. Показано, что атипичная вспышка азиатской холеры в 1942-1943 гг. в России была вызвана двумя фенотипически и филогенетически различными группами штаммов. Одна из которых была представлена ауксотрофами, являющимися гиперпродуцентами СТ, но не продуцирующими НА/Р, родственными ауксотрофному $\mathrm{HA} / \mathrm{P}^{-}$изоляту из Хабаровска (1938 г.), вторая - прототрофами, с низкой продуцией СТ, НА/ $\mathrm{P}^{+}$штаммами, имеющими общее происхождение со штаммами из Индии (1946 г.) и Китая (1949 г.). Полученные данные о близкородственном происхождении большинства атипичных штаммов и штамма из Хабаровска, отличавшихся отсутствием продукции НА/Р, которая на поздней стадии клинического процесса разрушает рецепторы кишечного эпителия, способствуя выходу холерного вибриона во внешнюю среду $[4,10]$, могут указывать на возможность длительного сохранения подобных штаммов в межвспышечный период в виде длительного вибрионосительства и развития латентных форм инфекции. В связи с тем, что указанный механизм открепления холерных вибрионов от клеток кишечного эпителия является общим для штаммов классического и Эль Тор биоваров, возможность длительного сохранения вибрионов, лишенных НА/Р, следует учитывать при проведении противоэпидемических мероприятий. 
Авторы приносят глубокую благодарность канд. хим. наук, зав. лаб. геномного и протеомного анализа Краснову Я.М. за помощь в построении филогенетического дерева.

Конфликт интересов. Авторы подтверждают отсутствие конфликта финансовых/нефинансовых интересов, связанных с написанием статьи.

\section{СПИСОК ЛИТЕРАТУРЫ}

1. Водопьянов А.С., Водопьянов С.О., Мишанькин М.Б., Сучков И.Ю. Вариабельные тандемные повторы, выявленные при компьютерном анализе генома Vibrio cholerae. Биотехнология. 2001; 6:85-8.

2. Покровский В.И., редактор. Холера в СССР в период VII пандемии. М.; 2000. 472 с.

3. Смирнова Н.И., Кульшань Т.А., Краснов Я.M. MLVAтипирование клинических штаммов Vibrio cholerae, изолированных в разные периоды текущей пандемии холеры. Мол. генет., микробиол. и вирусол. 2015; 1:15-22. DOI: 10.3103/ S0891416815010085.

4. Смирнова Н.И., Челдышова Н.Б., Заднова С.П., Кутырев В.В. Молекулярно-генетические особенности штаммов Vibrio cholerae classica, вызвавших эпидемию азиатской холеры в России в 1942 г. Мол. генет., микробиол. и вирусол. 2001; 4:12-6.

5. Челдышова Н.Б., Крицкий А.А., Краснов Я.М, Смирнова Н.И. Анализ результатов фрагментарного и полногеномного секвенирования атипичных штаммов Vibrio cholerae классического биовара, вызвавших вспышку азиатской холеры в России. Эпидемиол. и инф. бол. 2015; 20(5):24-31.

6. Alam M., Islam M.T., Rashed S.M., Johura F.T., Bhuiyan N.A., Delgado G., Morales R., Mendez J.L., Navarro A., Gil A.I., Watanabe H., Morita M., Nair B., Cravioto A. Vibrio cholerae classical biotype strains reveal distinct signatures in Mexico. J. Clin. Microbiol. 2012; 50 (7):2212-6. DOI:10.1128/JCM.00189-12.

7. Bakhshi B., Boustanshenas M., Mahmoudi-Aznaveh A. Emergence of Vibrio cholerae O1 classical biotype in 2012 in Iran. Lett. Appl. Microbiol. 2014; 58 (2):145-9. DOI:10.1111/lam.12167.

8. Choi S.Y., Lee J.H., Jeon Y.S., Lee H.R., Kim E.J., Ansaruzzaman M., Bhuiyan N.A.A., Endtz H.P., Niyogi S.K., Sarkar B.L., Nair G.B., Nguen B.M., Hien N.T., Czerkinsky C., Clemens J.D., Chun J., Kim D.W. Multilocus variable-number tandem repeat analysis of Vibrio cholerae O1 El Tor strains harbouring classical toxin B. J. Med. Microbiol. 2010; 59(7):763-9. DOI: 10.1099/ jmm.0.017939-0.

9. Dziejman M., Balon E., Boydet D., Fraser C.M., Heidelberg J.F., Mekalanos J.J. Comparative genomic analysis of Vibrio cholerae: genes that correlate with cholera endemic and pandemic disease. Proc. Natl. Acad. Sci. 2002; 99:1556-61. DOI: 10.1073/ pnas.042667999.

10. Hase C.C., Finkelstein R.A. Cloning and nucleotide sequence of the Vibrio cholerae hemagglutinin/protease (HA/Protease) gene and construction of an HA/Protease-negative strain. J. Bacteriol. 1991; 173:3311-17.

11. Kokashvili T, Elbakidze T, Jaiani E, Janelidze $\mathrm{N}$, Kamkamidze G, Whitehouse C., Huq A., Tediashvili M. Comparative phenotypic characterization of Vibrio cholerae isolates collected from aquatic environments of Georgia. Georgian Med. News. 2013; 224:55-62.

12. Longini I.M. Jr., Yunus M., Zaman K., Siddique A.K., Sack R.B., Nizam A. Epidemic and endemic cholera trends over a 33 -year period in Bangladesh. J. Infect. Dis. 2002; 186(2):246-51. DOI: 10.1086/341206.

13. Pun S.B. The first appearance of classical-like phenotype
Vibrio cholerae in Nepal. N. Am. J. Med. Sci. 2014; 6(4):183-4. DOI: 10.4103/1947-2714.131248.

14. Rai K.R, Rai S.K, Bhatt D.R, Kurokuwa M, Ono K, Magar D.T. Study of medically important Vibrios in the sewage of Katmandu Valley, Nepal. Nepal Med. Coll. J. 2012; 14(3):212-5.

\section{References}

1. Vodop'yanov A.S., Vodop'yanov S.O., Mishan'kin M.B., Suchkov I.Yu. [Variable tandem repeats, detected by means of computer-based analysis of Vibrio cholerae genome]. Biotekhnologiya. 2001; 6:85-8

2. Pokrovsky V.I., editor. [Cholera in the USSR during the VII Pandemic]. M.; 2000. 472 p.

3. Smirnova N.I., Kul'shan' T.A., Krasnov Ya.M. [MLVA-typing of clinical Vibrio cholerae strains, isolated in different periods of the current cholera pandemic]. Mol. Genet. Mikrobiol. Virusol. 2015; 1:15-22. DOI: 10.3103/S0891416815010085.

4. Smirnova N.I., Cheldyshova N.B., Zadnova S.P., Kutyrev V.V. [Molecular-genetic peculiarities of Vibrio cholerae classica strains, which caused Asian cholera pandemic in Russia in 1942]. Mol. Genet. Mikrobiol. Virusol. 2001; 4:12-6.

5. Cheldyshova N.B., Kritsky A.A., Krasnov Ya.M., Smirnova N.I. [Analysis of the results of fragment and whole genome sequencing of atypical Vibrio cholerae strains, classical biovar, which caused Asian cholera pandemic in Russia]. Epidemiol. Infek. Bol. 2015; 20(5):24-31.

6. Alam M., Islam M.T., Rashed S.M., Johura F.T., Bhuiyan N.A., Delgado G., Morales R., Mendez J.L., Navarro A., Gil A.I., Watanabe H., Morita M., Nair B., Cravioto A. Vibrio cholerae classical biotype strains reveal distinct signatures in Mexico. J. Clin. Microbiol. 2012; 50 (7):2212-6. DOI:10.1128/JCM.00189-12.

7. Bakhshi B., Boustanshenas M., Mahmoudi-Aznaveh A. Emergence of Vibrio cholerae O1 classical biotype in 2012 in Iran. Lett. Appl. Microbiol. 2014; 58 (2):145-9. DOI:10.1111/lam.12167.

8. Choi S.Y., Lee J.H., Jeon Y.S., Lee H.R., Kim E.J., Ansaruzzaman M., Bhuiyan N.A., Endtz H.P., Niyogi S.K., Sarkar B.L., Nair G.B., Nguen B.M., Hien N.T., Czerkinsky C., Clemens J.D., Chun J., Kim D.W. Multilocus variable-number tandem repeat analysis of Vibrio cholerae O1 Ei Tor strains harbouring classical toxin B. J. Med. Microbiol. 2010; 59(7):763-9. DOI 10.1099/jmm.0.017939-0

9. Dziejman M., Balon E., Boydet D., Fraser C.M., Heidelberg J.F., Mekalanos J.J. Comparative genomic analysis of Vibrio cholerae: genes that correlate with cholera endemic and pandemic disease. Proc. Natl. Acad. Sci. 2002; 99:1556-61. DOI: 10.1073/pnas.042667999.

10. Hase C.C., Finkelstein R.A. Cloning and nucleotide sequence of the Vibrio cholerae hemagglutinin/protease (HA/Protease) gene and construction of an HA/Protease-negative strain. J. Bacteriol. 1991; 173:3311-17.

11. Kokashvili T, Elbakidze T, Jaiani E, Janelidze N, Kamkamidze G, Whitehouse C., Huq A., Tediashvili M. Comparative phenotypic characterization of Vibrio cholerae isolates collected from aquatic environments of Georgia. Georgian Med. News. 2013; 224:55-62.

12. Longini I.M. Jr., Yunus M., Zaman K., Siddique A.K., Sack R.B., Nizam A. Epidemic and endemic cholera trends over a 33-year period in Bangladesh. J. Infect. Dis. 2002; 186(2):246-51. DOI: 10.1086/341206.

13. Pun S.B. The first appearance of classical-like phenotype Vibrio cholerae in Nepal. N. Am. J. Med. Sci. 2014; 6(4):183-4. DOI: 10.4103/19472714.131248.

14. Rai K.R, Rai S.K, Bhatt D.R, Kurokuwa M, Ono K, Magar D.T. Study of medically important Vibrios in the sewage of Katmandu Valley, Nepal. Nepal Med. Coll. J. 2012; 14(3):212-5.

Authors:

Cheldyshova N.B., Kritsky A.A., Lozovsky Yu.V., Guseva N.P. Russian Research Anti-Plague Institute "Microbe". 46, Universitetskaya St., Saratov, 410005, Russian Federation. E-mail: rusrapi@microbe.ru.

\section{Об авторах:}

Челдымова Н.Б., Криџкий А.А., Лозовский Ю.В., Гусева Н.П. Российский научно-исследовательский противочумный институт «Микроб». Российская Федерация, 410005, Саратов, ул. Университетская, 46. E-mail: rusrapi@microbe.ru 